Tatiana Messer Rybalowski

\title{
A Gestão da diferenciação de produtos de moda A inserção do artesanal na confecção industrial
}

Dissertação de Mestrado

Dissertação apresentada como requisito parcial para obtenção do grau de Mestre pelo Programa de PósGraduação em Design do Departamento de Artes \& Design da PUC-Rio

Orientador: Prof. Claudio Freitas de Magalhães 
Tatiana Messer Rybalowski

\section{A Gestão da diferenciação de produtos de moda} A inserção do artesanal na confecção industrial

Dissertação apresentada como requisito parcial para obtenção do grau de Mestre pelo Programa de PósGraduação em Design do Departamento de Artes \& Design do Centro de Teologia e Ciências Humanas. Aprovada pela Comissão Examinadora abaixo assinada.

Prof. Dr. Claudio Freitas de Magalhães

Orientador

Departamento de Artes \& Design - PUC-Rio

Prof ${ }^{a}$ Dra Sandra Regina Rech

UDESC

Prof. Dr. Alfredo Jefferson de Oliveira

Departamento de Artes \& Design - PUC-Rio

Prof. Dr. Paulo Fernando Carneiro de Andrade

Coordenador Setorial do Centro de

Teologia e Ciências Humanas - PUC-Rio

Rio de Janeiro, 6 de agosto de 2008 
Todos os direitos reservados. É proibida a reprodução total ou parcial do trabalho sem autorização do autor, do orientador e da universidade.

\section{Tatiana Messer Rybalowski}

Arquiteta graduada pela Universidade Federal do Rio de Janeiro em 1984, Técnica em Confecção em Estilismo Industrial pelo SENAI-CETIQT em 1987 e Especialista em Psicopedagogia pela Universidade Candido Mendes em 1999. Coordenadora acadêmica do Curso de Design de Moda da Universidade Candido Mendes.

Ficha catalográfica

Rybalowski, Tatiana Messer

A gestão da diferenciação de produtos de moda: a inserção do artesanal na confecção industrial / Tatiana Messer Rybalowski ; orientador: Claudio Freitas de Magalhães. 2008.

165 f. ; $30 \mathrm{~cm}$

Dissertação (Mestrado em Artes e Design) Pontifícia Universidade Católica do Rio de Janeiro, Rio de Janeiro, 2008.

Inclui bibliografia

1. Artes - Teses. 2. Design. 3. Moda. 4. Diferenciação. 5. Gestão de design. 6. Competitividade. I. Magalhães, Cláudio Freitas de. II. Pontifícia Universidade Católica do Rio de Janeiro. Departamento de Artes e Design. III. Título.

CDD:700 


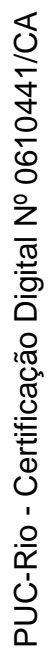

Para Victor, meu marido, meu amigo, minha luz 


\section{Agradecimentos}

Ao meu orientador Prof. Claudio Freitas de Magalhães, que acolheu as práticas da Moda no campo do Design;

À PUC, instituição que me trouxe tanto prazer na busca da contínua renovação do saber. 


\section{Resumo}

Rybalowski, Tatiana Messer; Magalhães, Claudio Freitas de. A Gestão da diferenciação do produto de moda: a inserção do artesanal na confecção industrial. Rio de Janeiro, 2008. 165p. Dissertação de Mestrado Departamento de Artes \& Design, Pontifícia Universidade Católica do Rio de Janeiro.

Dentre as diferentes formas que a moda tem para se manifestar, uma das mais expressivas é a indústria de vestuário. A despeito de sua essência mutável que busca constantemente a novidade, o produto de moda não tem conseguido ser diferente a ponto de revelar sua identidade através de seus atributos físicos. A partir da percepção de certa homogeneização do produto de moda, este trabalho busca trazer subsídios ao desenvolvimento de produtos diferenciados de moda através da criação de atributos físicos que reforcem a identidade do produto. Dentre vários recursos que podem ser utilizados, podem-se destacar os processos que inserem o artesanal na confecção industrial, resultando em peças únicas e construindo um contraponto ao excesso de industrialização, impessoalidade e repetição de modelos produzidos em escala unicamente industrial. Como uma ferramenta estratégica para a manutenção da competitividade através da diferenciação, a Gestão de Design utiliza as competências, conhecimentos e experiências da empresa a fim de possibilitar a contínua reinvenção de produtos e processos que coloquem a empresa numa posição de destaque no mercado.

\section{Palavras-chave}

Design; moda; diferenciação; gestão de design; competitividade. 


\section{Abstract}

Rybalowski, Tatiana Messer; Magalhães, Claudio Freitas de. Differentiated fashion product Management: handicraft meets apparel industry. Rio de Janeiro, 2008. 165p. Msc. Dissertation - Departamento de Artes \& Design, Pontifícia Universidade Católica do Rio de Janeiro.

Apparel is one of fashion's most expressive resources, and yet, in spite of its ever changing nature, the fashion product has not managed to achieve differentiation in a way that makes its physical attributes reveal its identity. Departing from a perception of a growing homogenization of fashion products, this study brings some insights for the development of differentiated fashion products through the use of physical attributes that reinforce a product's identity. Among the several strategies to achieve this aim, we may emphasize the processes that promote the merging of handicraft production and apparel industry, thus yielding unique items and disrupting the pattern of excessively industrialized, repetitive and impersonal products. As a strategic tool to maintain competitive advantage through differentiation, Design Management exploits a company's competence, knowledge and experience to continuously reinvent products and processes to achieve competitive positioning.

\section{Keywords}

Design; fashion; differentiation; design management; competitiveness. 


\section{Sumário}

Sumário $\quad 8$

$\begin{array}{ll}\text { Lista de Tabelas } & 11\end{array}$

$\begin{array}{lr}\text { Lista de Figuras } & 12\end{array}$

$\begin{array}{ll}\text { Introdução } & 13\end{array}$

$\begin{array}{ll}\text { A moda e o novo } & 13\end{array}$

As empresas de vestuário que se dedicam à moda 14

Homogeneização do produto de moda 19

$\begin{array}{ll}\text { Problema } & 20\end{array}$

Predição 22

Objeto 22

Objetivo 22

$\begin{array}{ll}\text { Justificativa da Pesquisa } & 23\end{array}$

Metodologia da Pesquisa 26

$\begin{array}{ll}\text { Organização da Pesquisa } & 27\end{array}$

1- A criação de diferenças na moda 29

1.1 A coleção de moda: a orquestração da renovação 30

1.2 Ciclos da moda e a obsolescência programada 31

1.3 Empresas de vestuário dedicadas à moda: puxadas pelo consumo e orquestradas pelo varejo $\quad 34$

1.4 A homogeneização do cenário: muitas ofertas e poucas escolhas 40

1.5 A necessidade contínua do novo: diferenciar para competir 44

2 - O produto diferenciado de moda 50

2.1 Moda e competitividade $\quad 51$

2.2 Produto de moda 53 
2.2.1 Quanto às estratégias de produção

2.2.2 Quanto às estratégias de comercialização 55

$2.3 \mathrm{O}$ produto diferenciado de moda 60

2.4 Formas de diferenciação do produto de moda 63

2.4.1 Diferenciação na coleção 64

2.4.2 Diferenciação no produto 73

2.5 A parceria do artesanal com o produto industrial $\quad 77$

2.6 Gestão do produto diferenciado de moda 83

2.7 Gestão do produto diferenciado de moda originado da inserção do artesanal no industrial $\quad 87$

3 - A Diferenciação no Mercado de Moda 92

3.1 Tipo de pesquisa 93

3.2 Coleta de dados $\quad 94$

3.3 Universo e amostra 95

3.4 Sujeitos das amostras $\quad 95$

3.5 Critérios para as escolhas das empresas 96

3.6 Questionários 97

3.6.1 Questionário $1 \quad 97$

3.6.2 Questionário 2

3.7 Apresentação dos dados $\quad 100$

3.7.1 Questionário $1 \quad 100$

3.7.2. Tabulação do Questionário $2 \quad 107$

3.8 Análise dos dados 113

3.8.1 Questionário: A percepção da diferenciação no produto de moda 113

3.8.2 Questionário 2: A diferenciação de marcas de moda com o artesanal inserido no industrial 116

4 - Conclusões 122

$\begin{array}{ll}\text { Bibliografia } & 127\end{array}$

$\begin{array}{ll}\text { Glossário } & 136\end{array}$ 
Anexos

1.1. Anexo 1 - Questionário 1

1.1.1. Questionário aplicado a profissionais, professores e estudantes de moda

1.2. Anexo 2 - Questionário 2

1.2.1. Questionário aplicado a empresas que possuem marcas com produtos diferenciados de moda originados da inserção do artesanal dentro dos processos de confecção industrial

1.3. Anexo 3 - Apresentação dos dados

1.3.1. Questionário da marca Farm

1.3.2. Questionário da marca Homem de Barro 147

1.3.3. Questionário da marca Osklen 154

1.4. Anexo 4 - Perfil das empresas pesquisadas 


\section{Lista de Tabelas}

Tabela 1 - Marcas com produtos diferenciados................................................ 101

Tabela 2 - Marcas com produtos diferenciados (respostas válidas) ........ 102

Tabela 3 - Percepção das diferenças .............................................................. 103

Tabela 4 - Categorização das diferenças ................................................... 104

Tabela 5 - Ocorrências das categorias de diferenciação.............................. 105

Tabela 6 - Marca com diferencial no artesanal .............................................. 106

Tabela 7 - Marca com diferencial no artesanal (respostas válidas) .......... 107 


\section{Lista de Figuras}

Figura 1 - Estrutura Hierárquica de Gestão de Moda..............................66

Figura 2 - Bolero com diversas aplicações (crochê, tecido, argolas e contas), estilo Fernando de Paiva ........................................... 79

Figura 3 - Aplicação de "paetês" de tecido e miçangas, estilo Homem de Barro 80

Figura 4 - Detalhe da aplicação de "paetês" de tecido e miçangas, estilo Homem de Barro. 80

Figura 5 - Aplicação de contas, sianinhas, fitas, cadarços, tachas e miçangas, estilo Isabela Capeto 81

Figura 6 - Aplicação de tecido com trabalho de pesponto e pespontos com linha contrastante executados de forma aleatória na gola, estilo Homem de Barro 82 